\title{
PROPRIEDADES DE REVESTIMENTOS AISI 904L DEPOSITADOS PELO PROCESSO ELETROESCÓRIA*
}

\author{
Orlando Guerreiro Meira ${ }^{1}$ \\ Francisco Carlos Albuquerque Madalena ${ }^{1}$ \\ Leonardo Sales Araújo ${ }^{2}$ \\ Luis Felipe Guimarães de Souza ${ }^{3}$ \\ Jorge Carlos Ferreira Jorge ${ }^{3}$ \\ Matheus Campolina Mendes ${ }^{4}$
}

\section{Resumo}

A utilização de revestimentos com aços inoxidáveis superausteníticos em substituição às ligas a base de níquel na indústria de óleo e gás pode ser uma alternativa interessante, uma vez que é possível a manutenção de bom desempenho e corrosão com um menor custo. O presente trabalha avalia as propriedades mecânicas e microestruturais de revestimentos depositados com a liga AISI 904L sobre o aço carbono ASTM A 516 pelo processo eletroescória, tanto na condição de como soldado quanto após tratamento térmico de alívio de tensões. Após a soldagem, foram realizados ensaios mecânicos e metalográficos para verificar o efeito do ciclo térmico de soldagem nas propriedades do revestimento. $O$ ensaio de dobramento não mostrou indicação de defeitos, sendo considerado aprovado. Os ensaios de microdureza apresentaram valores inferiores a $300 \mathrm{HV}_{0.5}$, em decorrência da microestrutura austenítica com baixo percentual de fases secundárias no metal de solda e de bainita na ZTA. O tratamento térmico de alívio de tensões não provocou mudanças significativas nas propriedades do revestimento.

Palavras-chave: Revestimentos; Aços superausteníticos; Propriedades mecânicas.

\section{PROPERTIES OF THE AISI 904L ALLOY WELD OVERLAY DEPOSITED BY ELECTROSLAG PROCESS}

\section{Abstract}

The application of the Superaustenitic Stainless Steel (SASS) overlay to replace superalloys based in nickel used in oil \& gas industry can be an interesting alternative due to their lower costs. The present work evaluates mechanical and microstructural properties of AISI 904L steel weld overlay deposited on a ASTM A516 Grade by Electro Slag Welding process (ESW), both in as welded and stress relieved conditions. After welding, mechanical tests and metallographic examination were conducted in order to verify possible effects of welding thermal cycle on the mechanical and microstructural properties. Bending tests showed satisfactory results once no defects were found. Hardness tests showed results lower than $300 \mathrm{HV}$ due to the presence of austenite with low proportion of secondary phases in weld metal and bainite in heat affected zone. In addition, partially diluted zones were not observed at the interface. Post weld heat treatment did not promote substantial changes on the properties.

Keywords: Weld overlay; Superaustenitic stainless steel; Mechanical properties.

Eng. Mecânico, M.Sc., Engenheiro, PETROBRAS, Rio de Janeiro, RJ, Brasil.

Eng. Metalúrgico, D.Sc., Professor Adjunto da UFRJ, Rio de Janeiro, RJ, Brasil.

Eng. Metalúrgico, D.Sc., Professor Titular do CEFET/RJ, PPEMM, Rio de Janeiro, RJ, Brasil.

Eng. Metalúrgico, M.Sc., Professor Assistente do CEFET/RJ, CEMEC, Rio de Janeiro, RJ, Brasil. 


\section{INTRODUÇÃO}

A busca por um material econômico com maior resistência à corrosão em ambientes com cloretos e com boas propriedades mecânicas ganhou impulso nos últimos anos, devido à necessidade de exploração de petróleo e gás sob a camada de pré-sal. Um material candidato é o aço inoxidável superaustenítico (AISA) [1]. O termo superaustenítico refere-se ao aço inoxidável austenítico contendo quantidades elevadas de molibdênio, cromo, níquel e nitrogênio [2]. A utilidade dos aços AISA é particularmente interessante porque eles preenchem a lacuna custo-qualidade entre o aço inoxidável austenítico relativamente mais barato e as superligas a base de níquel mais caras [3,4]. A microestrutura do aço inoxidável superaustenítico é constituída por austenita, sendo que o elevado teor dos elementos $\mathrm{Mo}, \mathrm{Cr}$ e $\mathrm{N}$ pode favorecer a precipitação de fases intermetálicas, tais como sigma, chi e Laves, reconhecidamente prejudiciais para as propriedades mecânicas e de corrosão $[1,4,5]$.

O aço AISI 904L é um aço inoxidável austenítico de baixo carbono e alta liga que apresenta elevada tenacidade ao impacto e boa soldabilidade, devido ao seu alto teor de molibdênio, que minimiza a formação de trincas a quente na soldagem $[4,6]$. Este aço apresenta um resistência à corrosão substancialmente maior que os aços inoxidáveis da série 300 [6].

De acordo com Bogdanowicz et al. [6], apesar da ampla gama de utilização de aço superaustenítico AISI 904L na indústria, a pesquisa das propriedades deste material na literatura ainda é limitada. Considerando que este aço é uma alternativa atraente para algumas aplicações, mesmo em instalações offshore que têm requisitos muito rigorosos para aprovação [7], é importante o estudo do efeito do ciclo térmico de soldagem nas propriedades mecânicas e microestruturais deste aço.

Uma outra questão interessante, envolve a realização de revestimentos de ligas resistentes à corrosão sobre aços carbono como alternativa ao uso de materiais de elevado custo. Por razões de economia, vasos de pressão de paredes grossas podem ser produzidos por revestimento com uma ou mais camadas de AISA, com economina substancial de custos de fabricação [8]. Neste aspecto, Kahar et al. [9] afirmam que os dois processos mais produtivos para revestimentos de grandes componentes são os processos a arco submerso e eletroescória com utilização de fita, por permitirem a deposição com qualidade, elevada taxa de deposição e baixa diluição, sendo este último processo com um único passe é mais recomendado em situações onde se precisa de baixa diluição [10].

Este trabalho avalia as propriedades mecânicas e microestruturais de revestimentos depositados com a liga AISI 904L sobre o aço carbono ASTM A 516 grau 70, tanto na condiçao de como soldado quanto após tratamento térmico de alívio de tensões (TTAT).

\section{MATERIAIS E MÉTODOS}

\subsection{Materiais}

Uma chapa de aço carbono ASTM A516 Gr. 70 de dimensões 50 x 400 x 400 mm foi utilizada como o material de substrato. Uma fita com as dimensões $0,5 \times 60 \mathrm{~mm}$ de largura da classe AWS A 5.9:EQ 385 [11] e um fluxo (E) FB 2CrNiMo de acordo com EN 760 [12] foram usados para produzir o revestimento com a liga AISI 904L. A Tabela 1 mostra a composição química dos materiais. 
Tabela 1. Composição química dos materiais (\% Peso).

\begin{tabular}{c|c|c|c|c|c|c|c}
\hline Elemento & C & Si & Mn & Ni & Cr & Mo & Cu \\
\hline ASTM A516 Gr.70 & 0,23 & 0,24 & 1,11 & 0,02 & 0,02 & 0,01 & - \\
\hline AISI 904L & 0,01 & 0,20 & 1,00 & 25,0 & 20,2 & 6,1 & 1,3 \\
\hline
\end{tabular}

\subsection{Soldagem}

Os revestimentos foram depositados pelo processo eletroescória com fita em três passes com camada única na posição plana de soldagem. Utilizaram-se temperaturas de preaquecimento e de interpasse de $15^{\circ} \mathrm{C}$ e $150^{\circ} \mathrm{C}$, respectivamente e os parâmetros de soldagem mostrados na Tabela 2.

Tabela 2. Parâmetros de soldagem utilizados.

\begin{tabular}{c|c|c|c|c}
\hline $\begin{array}{c}\text { Corrente } \\
\text { (A) }\end{array}$ & $\begin{array}{c}\text { Tensão } \\
\text { (Volts) }\end{array}$ & $\begin{array}{c}\text { Energia de soldagem } \\
\text { (kJ/mm) }\end{array}$ & $\begin{array}{c}\text { Número de } \\
\text { Passes }\end{array}$ & $\begin{array}{c}\text { Número de } \\
\text { Camadas }\end{array}$ \\
\hline $1150-1250$ & $24-26$ & 11,7 & 3 & 1 \\
\hline
\end{tabular}

Após a soldagem, foram realizados tratamentos térmicos consistindo de aquecimento a $620^{\circ} \mathrm{C}$ por 10 horas, seguido de resfriamento ao ar, sendo esta condição comparada à condição de como soldado do metal de solda.

\subsection{Ensaios Mecânicos}

Foram realizados ensaios de microdureza Vickers com aplicação de carga de 500 gf., consistindo de varredura de dureza perpendicularmente à linha de fusão, com espaçamento das impressões de $0,25 \mathrm{~mm}$. Foram ainda realizados ensaios de dobramento de acordo com a norma ASME Seção IX [13].

\subsection{Ensaios Metalográficos}

Realizou-se análise metalográfica, consistindo de macrografia, micrografia ótica (MO) e microscopia eletrônica de varredura (MEV) e análise por espectroscopia de energia dispersiva (EDS) e difração de elétrons retroespalhados (EBSD) para caracterizar a microestrutura, identificação e quantificação de fases secundárias e ocorrência de zonas parcialmente diluídas próximas à linha de fusão. Para a análise quantitativa das fases secundárias, utilizou-se a técnica da contagem por pontos em grade metalográfica com 100 pontos na tela do MEV e aumento de 1.000 vezes. Foram contados aleatoriamente pelo menos 10 campos para cada condição, perfazendo um total de 1.000 pontos por amostra, localizados na posição relativa à $3 \mathrm{~m}$ da linha de fusão. Foi ainda realizada análise de simulação de fases secundárias com auxílio do software thermocalc.

A preparação das amostras consistiu da técnica convencional de lixamento e polimento, seguido de ataque químico com reagente nital $2 \%$ para o metal base e ataque eletrolítico com uma solução de $20 \% \mathrm{CrO}_{3}$ e $80 \%$ de água destilada, utilizando 4 Volts durante 30 segundos.

\subsection{Análise Química}

Foram realizadas análises químicas dos revestimentos por espectrometria de emissão ótica para avaliação da composição química e da diluição ao longo do perfil 
do metal de solda. As análises foram realizadas nas regiões correspondentes à linha de fusão e às distâncias de 1, 2,4 e 6,5 mm a partir da linha de fusão.

\section{RESULTADOS E DISCUSSÃO}

As características do revestimento podem ser vistas na Figura 1, onde é possível observar uma única camada com baixa taxa de diluição, tal como esperado para o processo eletroescória. A taxa de diluição de $4,0 \%$, calculada com o auxílio do software Auto CAD, pode ser considerada baixa quando comparada com outros processos. Para o processo MIG, por exemplo, uma taxa de $11,2 \%$ foi observada em outros estudos [14].

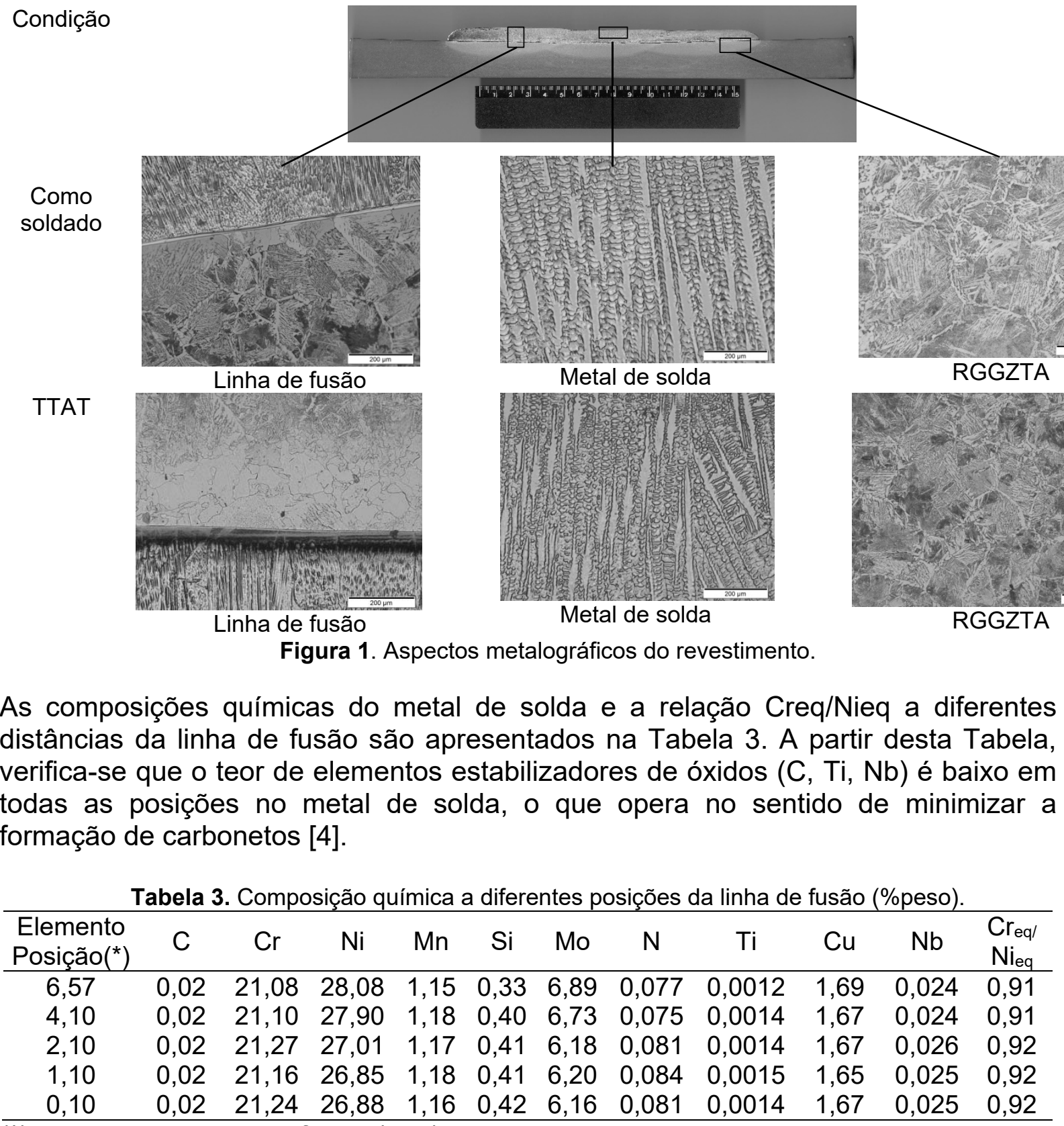

$\left(^{*}\right)$ distância da linha de fusão (mm). 
Adicionalmente, pode ser notada a ocorrência de uma microestrutura austenítica (Figura 1) com grãos grosseiros (Figura 2), o que está de acordo com as afirmações de David et al. [15], que elaboraram um diagrama de Schaeffler modificado incorporando as elevadas taxas de resfriamento envolvidas no processo de soldagem, onde uma proporção de Creq/Nieq inferior de 1,35 resulta na solidificação austenítica. Foi também verificado um elevado nível de segregação (Figura 3), provocando diferenças significativas na composição da austenita nas regiões dendríticas (D) e interdendríticas (ID) e a ocorrência de fases secundárias (Figura 3).
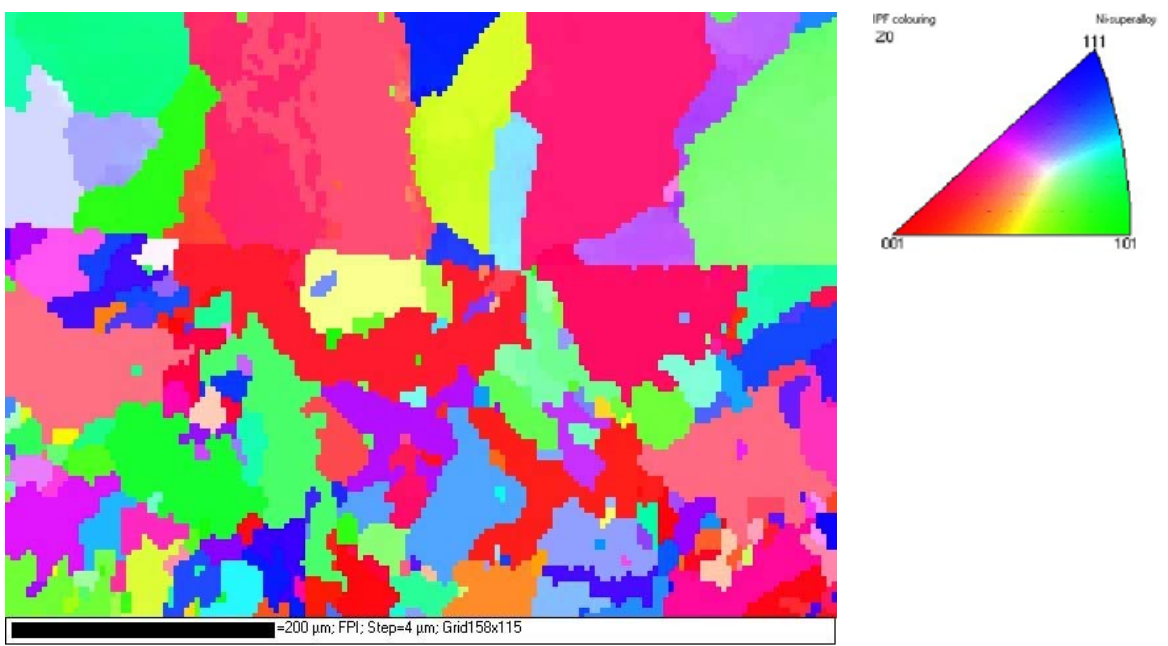

Figure 2. Figura de polo invertida obtida por EBSD na linha de fusão.

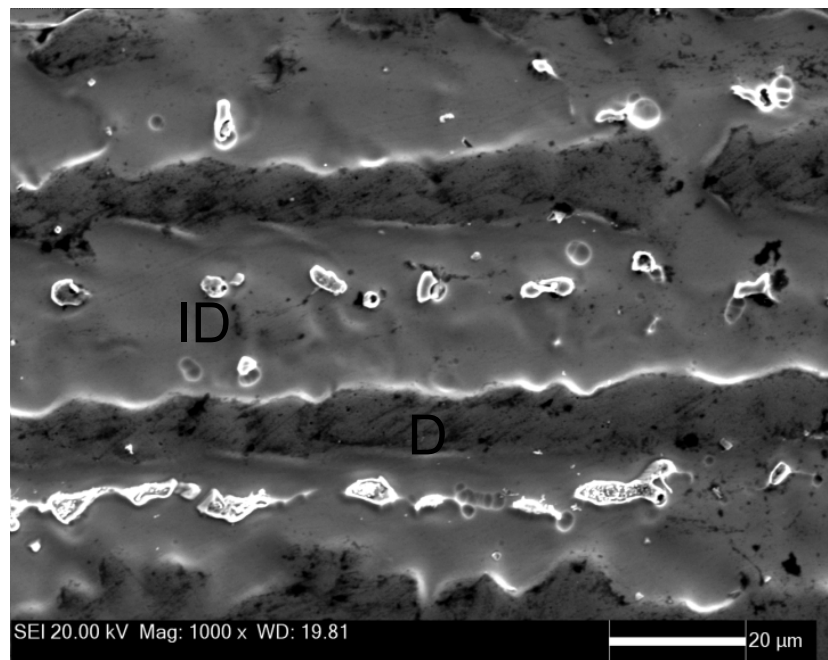

Figure 3. Microestrutura do metal de solda (MEV), destacando as regiões dendrítica (D) e interdendrítica (ID)

Alguns estudos $[1,3,4,16]$ mostraram que as fases intermetálicas mais comumente observadas em metais de solda de aço AISI 904L são as fases sigma, chi ou Laves. Em alguns casos, estas fases são tratadas como uma única, devido à sua morfologia muito semelhante [3]. De acordo com Barbosa et al. [3], existe uma competição entre estas fases, sendo o efeito de elementos de liga na composição química é o fator de controle para a ocorrência de cada fase. Neste aspecto, o teor de Cromo na fase sigma pode atingir até $30 \%$, enquanto o teor de Molibdênio pode variar de $15 \%$ a $20 \%$. A fase Chi apresenta um teor de Cromo similar a da fase sigma, mas com um teor mais elevado de Molibdênio [17]. 
Para a previsão das fases formadas, foi calculado um diagrama pseudo-binário com a variação do elemento Molibdênio no eixo das abscissas, em função do potencial de segregação deste elemento no líquido, durante a solidificação proveniente da soldagem, com auxílio do software Thermocalc e utilizando a base de dados para aços TTFE6. A composição utilizada foi do metal de solda a $3 \mathrm{~mm}$ da linha de fusão. A Figura 4 mostra o diagrama. A execução da soldagem multipasse e posterior tratamento térmico por 10 horas a $620^{\circ} \mathrm{C}$ favorece a análise por meio de diagramas pseudo-binários ao invés das análises baseadas nas equações de Scheil e ScheilGulliver, as quais mostram o potencial de solidificação das fases. No diagrama (Figura 4), observa-se a primazia da formação da fase sigma para temperaturas mais altas. Contudo, esta possui uma grande região de interseção com a fase de Laves, principalmente para teores de Mo acima de 10\%. Para segregações de Mo entre cerca de 2 e $17 \%$ e temperaturas abaixo de $900^{\circ} \mathrm{C}$ pode ser formada fase Chi, oriunda principalmente da fase de Laves, apesar de permitir uma competição com a fase Sigma para teores de Mo entre 8 e 17\%. Mesmo havendo tal zona de interseção, os cálculos termodinâmicos realizados na temperatura de tratamento térmico $\left(620^{\circ} \mathrm{C}\right)$ indicam que as fases Chi e Sigma são preferencialmente formadas à fase de Laves.

THERMO-CALC (2016.01.25:15.48) :

DATABASE:TCFE6

$\mathrm{N}=1, \mathrm{P}=1.01325 \mathrm{E} 5, \mathrm{~W}(\mathrm{C})=4.16 \mathrm{E}-4, \mathrm{~W}(\mathrm{NI})=0.2485, \mathrm{~W}(\mathrm{CR})=0.1895, \mathrm{~W}(\mathrm{MN})=4.34 \mathrm{E}-2$, $\mathrm{W}(\mathrm{SI})=1.02 \mathrm{E}-2, \mathrm{~W}(\mathrm{CU})=1.822 \mathrm{E}-2, \mathrm{~W}(\mathrm{NB})=4.4 \mathrm{E}-4, \mathrm{~W}(\mathrm{~N})=1.414 \mathrm{E}-3$;

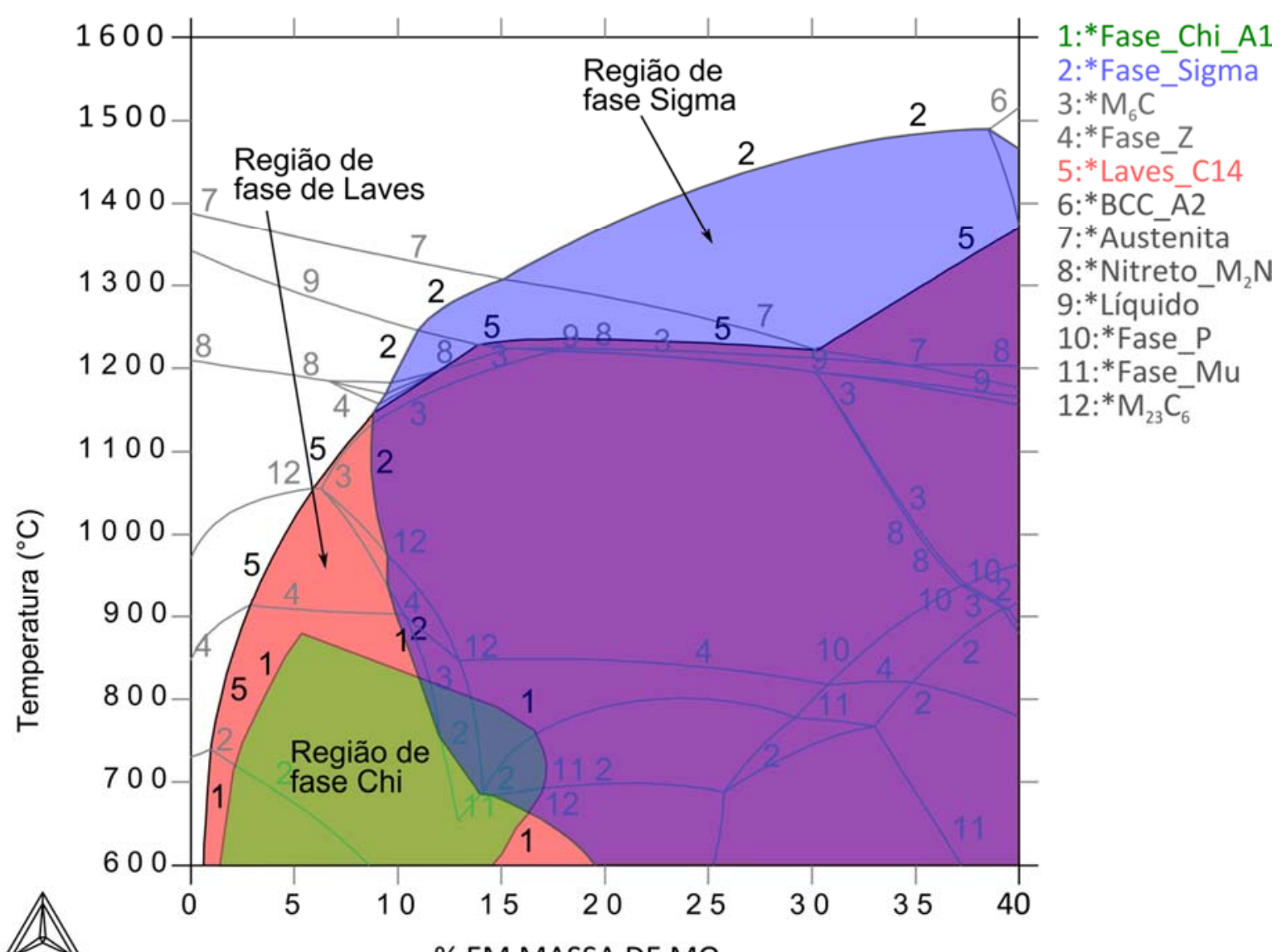

$\%$ EM MASSA DE MO

Figura 4. Diagrama pseudo-binário em função do Mo para composição do metal de solda a $3 \mathrm{~mm}$ da LF. A região hachurada em azul mostra a região de formação de fase sigma. A região vermelha mostra a região para a fase de Laves e a região verde para a fase Chi. Nota-se uma grande zona de interseção entre a fasede Laves e sigma. 
Considerando o acima exposto, a baixa proporção $(<1,0 \%)$ de fases secundárias observadas por MEV (Figura 5) e analisadas por EDS (Tabela 4), foram caracterizadas como fases Chi e sigma. Estes resultados são consistentes com os registrados por outros autores [1,3-5,16-18].

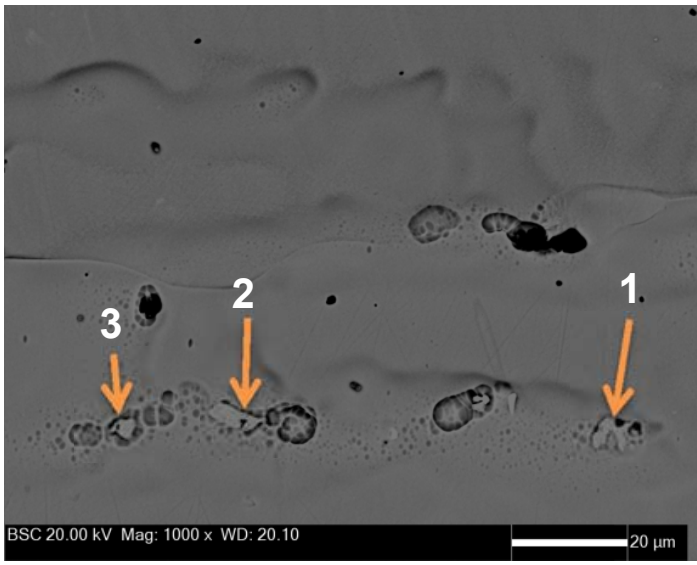

Como soldado

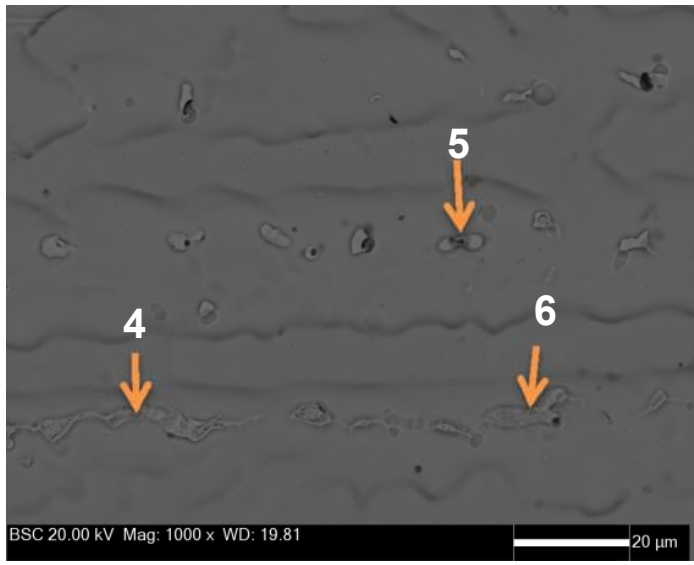

TTAT

Figura 5. Imagens por MEV no modo retroespalhado das fases secundárias do metal de solda.

Tabela 4. Análise das fases secundárias e matriz austenítica por EDS (\% peso).

\begin{tabular}{cccccc}
\hline Conditição & Posição & $\mathrm{Cr}$ & $\mathrm{Mo}$ & $\mathrm{Ni}$ & $\mathrm{Fe}$ \\
\hline Como soldado & ID & 23,43 & 8,34 & 25,97 & 43,58 \\
& $\mathrm{D}$ & 22,15 & 5,43 & 25,46 & 46,85 \\
& 1 & 27,76 & 26,89 & 14,23 & 31,12 \\
& 2 & 27,02 & 28,26 & 14,34 & 30,39 \\
TTAT & 3 & 25,99 & 24,71 & 16,72 & 32,58 \\
TTAT & 4 & 28,22 & 15,93 & 18,51 & 37,34 \\
TTAT & 5 & 27,21 & 28,52 & 14,73 & 29,54 \\
\end{tabular}

Devido à elevada energia de soldagem, uma microestrutura composta por bainita, perlita e ferrita pro-eutetóide foi observada na região de grãos grosseiros da ZTA (RGGZTA) (Figura 1), com valores de dureza inferiores a 300 HV (Figura 6), o que contribui sobremaneira para a qualidade do revestimento, ratificado pelos resultados nos ensaios de dobramento a $180^{\circ} \mathrm{C}$, que não apresentaram evidências de defeitos ou trincas. Este resultado é importante, porque normalmente uma microestrutura martensítica é observada nesta região para outros processos de soldagem [14,19].

Embora o TTAT possa promover a ocorrência de fases secundárias que são prejudiciais às propriedades dos aços AISA [1,4], este tratamento pode ser necessário para aliviar tensões residuais de componentes $[3,20]$. No presente trabalho, o TTAT realizado a $620^{\circ} \mathrm{C}$ não causou alterações significativas em relação à condição de como soldado, uma vez que a dureza não se alterou de forma significativa (Figura 6) e os resultados dos ensaios de dobramento a $180^{\circ}$ também foram aprovados sem incidência de defeitos, o que pode ser associado com a baixa proporção das fases secundárias mesmo após o TTAT. No caso da ZTA, o TTAT promoveu o revenimento da microestrutura com redução da dureza (Figura 6). 


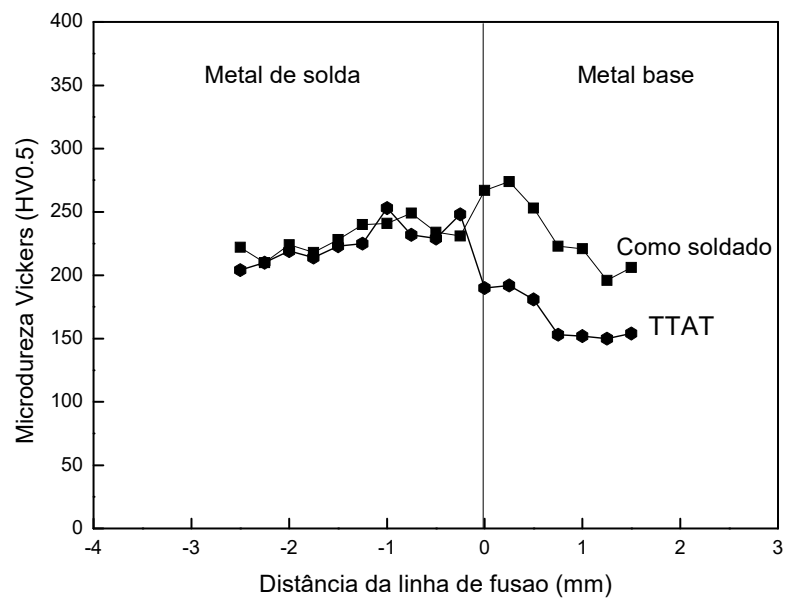

Figura 6. Resultados dos ensaios de microdureza.

Finalmente, a baixa diluição e uma elevada energia de soldagem também contribuíram para evitar a ocorrência de Zonas Parcialmente Diluídas (ZPD) na linha de fusão, tal como confirmado por análise EBSD (Figura 3) e ensaios de dureza (Figura 6), que mostrou resultados inferiores a $350-400 \mathrm{HV}$, valores geralmente associados à ocorrência de ZPD [14,21,22]. Este é um resultado importante, considerando os riscos de falhas associadas com a presença destas regiões $[21,23,24]$.

\section{CONCLUSÃO}

Do exposto no transcurso do presente trabalho, pode-se concluir que:

a) Foi observada uma microestrutura austenítica no metal de solda com baixa proporção de fases secundárias, identificadas como fases Chi e Sigma;

b) A microestrutura da RGGZTA foi predominantemente bainítica devido à baixa velocidade de resfriamento;

c) Não foi observada a presença de ZPD;

d) O TTAT realizado a $620^{\circ} \mathrm{C}$ não promoveu mudanças significativas nas propriedades do revestimento;

e) A aplicação de revestimentos metálicos utilizando a liga AISI 904L pode ser realizada pelo processo ESW com boa qualidade de deposição.

\section{Agradecimentos}

Os autores agradecem às seguintes Instituições pelo apoio prestado na execução do presente trabalho: CEFET/RJ, PETROBRAS, UFRJ, CNPq e FINEP.

\section{REFERÊNCIAS}

1 Anburaj J, Nazirudeen SSM, Narayanan R, Anandavel B. e Chandrasekar A. Ageing of forged superaustenitic stainless steel: precipitate phases and mechanical properties, Materials Science and Engineering A, 2012;535:99- 107.

2 Bang K, Pak S e Ahn S. Evaluation of weld metal hot cracking susceptibility in superaustenitic stainless steel, Metals and Materials International, 2013;19(6):12671273.

3 Barbosa BARS. Influência da microestrutura nas propriedades mecânicas e de corrosão do aço inoxidável superaustenítico AISI 904L, Dissertação de mestrado, 2011, Universidade Federal Fluminense, Rio de Janeiro, Brasil. 
4 Sathiya P, Aravindan S, Atjith PM, Arivazhagan B e Noorul Haq A. Microstructural characteristics on bead on plate welding of AISI $904 \mathrm{~L}$ super austenitic stainless steel using Gas metal arc welding process, International Journal of Engineering, Science and Technology, 2010;2(6):189-199.

5 Koutsoukis T, Redjaımia A e Fourlaris G. Phase transformations and mechanical properties in heat treated superaustenitic stainless steels, Materials Science \& Engineering A, 2013;561:477-485.

6 Bogdanowicz Z, Jozwik P e Nasilowska B. Microstructure and mechanical behavior of a CO2 laser and TIG welded 904L steel, Metallurgy and Foundry Engineering, 2014;40(2):69-81.

7 Norsok Standard, M-001, Materials Selection, Rev.3, 2002, Norway.

8 Yunjian W, Patchett BM e Bicknell C. The interfacial microstructure of weld overlay of corrosion resistant alloys, Scripta Metallurgica \& Materialia, 1994;30(9):1133-1138.

9 Kahar SD e Baba Pai K. Corrosion behavior of electro-slag strip cladded weld overlays in different acid solutions, International Journal of Engineering Research and Applications, 2013;3(4):2620-2627.

10 Paschold R, Karlsson L e Gittos MF. Disbonding of austenitic weld overlays in hydroprocessing applications, Svetsaren, 2007;62(1):10-15.

11 American Welding Society, Specification for Bare Stainless Steel Welding Electrodes and Rods, AWS A5.9/A5.9M:2006, 2006.

12 European Norm, Welding consumables. Fluxes for submerged arc welding. Classification EN-760, 1996.

13 ASME IX, Qualification Standard for Welding and Brazing Procedure, Welders, Brazers and Welding and Brazing Operator, 2012, USA.

14 Madalena FCA, Jorge JCF, Souza LFG, Costa HRM e Cabral TB. Estudo das propriedades mecânicas e microestruturais do aço inoxidável superaustenítico AISI 904L usado como revestimento interno em vasos de pressão fabricados em aço carbono ASTM A-516 grau 70, Anais do $7^{\circ}$ Congresso Brasileiro de Engenharia de Fabricação, 2013;1-13, Rio de Janeiro, Brasil.

15 David SA, Vitek JM e Hebble TL. Effect of rapid solidification on stainless steel weld metal, Welding Journal, 1987;66(10):289s-300s.

16 Barbosa BARS, Mainier FB, Pardal JM e Tavares SSM. Influência da solubilização na resistência a corrosão de revestimento tipo "clad de aço inoxidável AISI 904L, Corrosão e Proteção, 2013;49(10):28-33.

17 Pereira GBH. Influência do grau de deformação na cinética de precipitação de fases intermetálicas de aços inoxidáveis duplex UNS S31803 and lean duplex UNS S32304, Dissertação de Mestrado, 2014, UFRJ, Rio de Janeiro, Brasil.

18 Hsieh C e Wu W. Overview of intermetallic sigma $(\sigma)$ phase precipitation in stainless Steels, ISRN Metallurgy, 2012, Article ID 732471, P1-16, doi:10.5402/2012/732471

19 Alvarães CP, Madalena FCA, Araújo LS, Souza LFG e Jorge JCF. Propriedades de revestimentos de liga Inconel 625 obtidos pelos processos arame tubular e eletrodo revestido, 2015, Anais do $70^{\circ}$ Congresso Anual da ABM, p.1-11.

20 Satari-Far I e Andersson M. Cladding effects on structural integrity of nuclear components, 2006, SKI Report 2006:23

21 Rowe MD, Nelson TW e Lippold J C. Hydrogen-induced cracking along the fusion boundary of dissimilar metal welds, Welding Journal, 1999;78(2):31s-37s.

22 Silva VG. Avaliação da suceptibilidade à corrosão sob tensão do aço inoxidável superduplex UNS S32750 soldado pelo processo TIG orbital em meios contendo Cl-, CO2 E H2S, 2012, UFF, Niterói, Brazil.

23 Kejelin NZ, Buschinelli AJA e Bohórquez CEN. Dissimilar metal welding of X-60 steel with Inconel 625, 2006, Anais do $32^{\circ}$ Congresso Brasileiro de Soldagem, p.1-12.

24 Omar AA. Effects of welding parameters on hard zone formation at dissimilar metal welds, Welding Journal, 1998;77(2):83s-93s.. 